\title{
AFFECTATION OF CHIP FORMATION IN SINGLE-LIP DEEP HOLE DRILLING AT SMALL DIAMETERS BY APPLICATION OF LOW-FREQUENCY VIBRATION SUPPORT
}

\author{
M. Reiter ${ }^{1 *}$, F. Bleicher ${ }^{1}$ \\ ${ }^{1}$ IFT - Institute of Production Engineering and Photonic Technologies, TU Wien, Vienna, Austria \\ *Corresponding author; e-mail: reiter@ift.at
}

\begin{abstract}
Deep hole drilling processes are relevant for various applications where bore holes with high length-todiameter-ratios $(L / D)$ and good surface qualities are necessary, carried out mostly at the end of the (machining) process chain. Therefore, the avoidance of tool breakage and the resulting process stability is mandatory. One of the main causes for the failure of single-lip drills in the machining of long-chipping materials is the inadequate chip removal along the tool's flute. A successful approach to promote active chip breakage is the use of adequate/matching vibration-assistance, either of the tool or the workpiece. The aim of this work is to demonstrate the positive influence of low-frequency and high-amplitude vibration-assistance on the chip formation of age-hardened copper-zirconium, performed by solid carbide single-lip drills with small diameters (down to $0.94 \mathrm{~mm}$, hence a micro-drilling) and $L / D$-ratios up to 40 . The improvements of this deep hole drilling process reflect in significant increases in chip removal rate and thus productivity.
\end{abstract}

Keywords:

Deep hole drilling; Long-chipping material; Vibration; Chip formation; Material removal

\section{INTRODUCTION AND MOTIVATION}

Twist drilling is the most common drilling method, as it is a simple and low cost application; however, it has some disadvantages making it inappropriate for specific manufacturing tasks. The most important aspects for the use of deep hole drilling (DHD) methods are the realizable drilling diameter and the drilling length. One of these drilling types is single-lip deep hole drilling (SLD) with its asymmetrical single-edged tool design and the typically reachable diameter range of $D=0.5 \mathrm{~mm}$ up to $80 \mathrm{~mm}$ and length-to-diameter-ratios up to $L / D=400$ (in special applications even $L / D=900$ [Biermann 2018]). As the mixture of chips and cutting fluid is removed along the tool's flute, unfavorable chip formation may harm the surface quality of the bore hole. Moreover, the mechanical and thermal stresses on the tool are significantly increased the more long-chipping the processed workpiece material is, and chip jamming combined with following tool failure becomes more probable.

CuCr1Zr (2.1293, CW106C, C18150) features high strength values even for high temperatures, high wear resistance and high softening temperature. Its main characteristic in age-hardened state is the high electrical and thermal conductivity, so its primary area of application are electrical engineering and as contact material in mechanical engineering. Its machinability is of moderate to bad state, as the chip shape is unfavorable with mostly thread chips [DKI 2005, DKI 2010, Nobel 2013].

The single-lip drills for the present investigation are made of uncoated cemented carbide with diameters of $0.94 \mathrm{~mm}$, $1.40 \mathrm{~mm}$ and $1.84 \mathrm{~mm}$. With reference to VDI 3208
[VDI 2014], a standardized tip geometry and circumferential guiding pad arrangement are used for this range of tool diameters (Fig. 1).

Indicative values for reliable process parameters in conventional SLD were identified by initial drilling tests for the given tool configuration and process constraints. As also illustrated in Fig. 1, the results for the maximum admissible feed $f_{\max }$ were empirically determined with respect to unfavorable chip shapes (chip volume ratio $\geq 30$, marked by black rectangles). The yellow highlighted process area is defined by recurring propagation of discontinuous chip and coolant evacuation.

By implementation of vibration to the tool or workpiece, of which frequency and amplitude are adjusted to the specific manufacturing purpose and its cutting parameters, the machining of long-chipping materials is forced to generate small chips that can be evacuated more easily from the bore hole along the tool's flute. Furthermore, due to the intermitted cutting (as long as the vibration stroke $A_{v s, p-p}$ exceeds the feed $f$ ), the peak values of the mechanical stresses may be higher, but the average forces on the tool are decreased. This is based on the varying uncut chip thickness and the related non-linear increase of the specific cutting force. In addition, the thermal condition at the cutting edge is improved, as it is steadily wetted with cutting fluid when the tool is currently not engaged [Okamura 2006]. The generating of vibration can be realized by piezoelectric, hydro-mechanical or electro-magnetic principles; in prior applications mostly based on mechanical principles [Brehl 2008, Bleicher 2018, Pecat 2014, Sadek 2014]. 

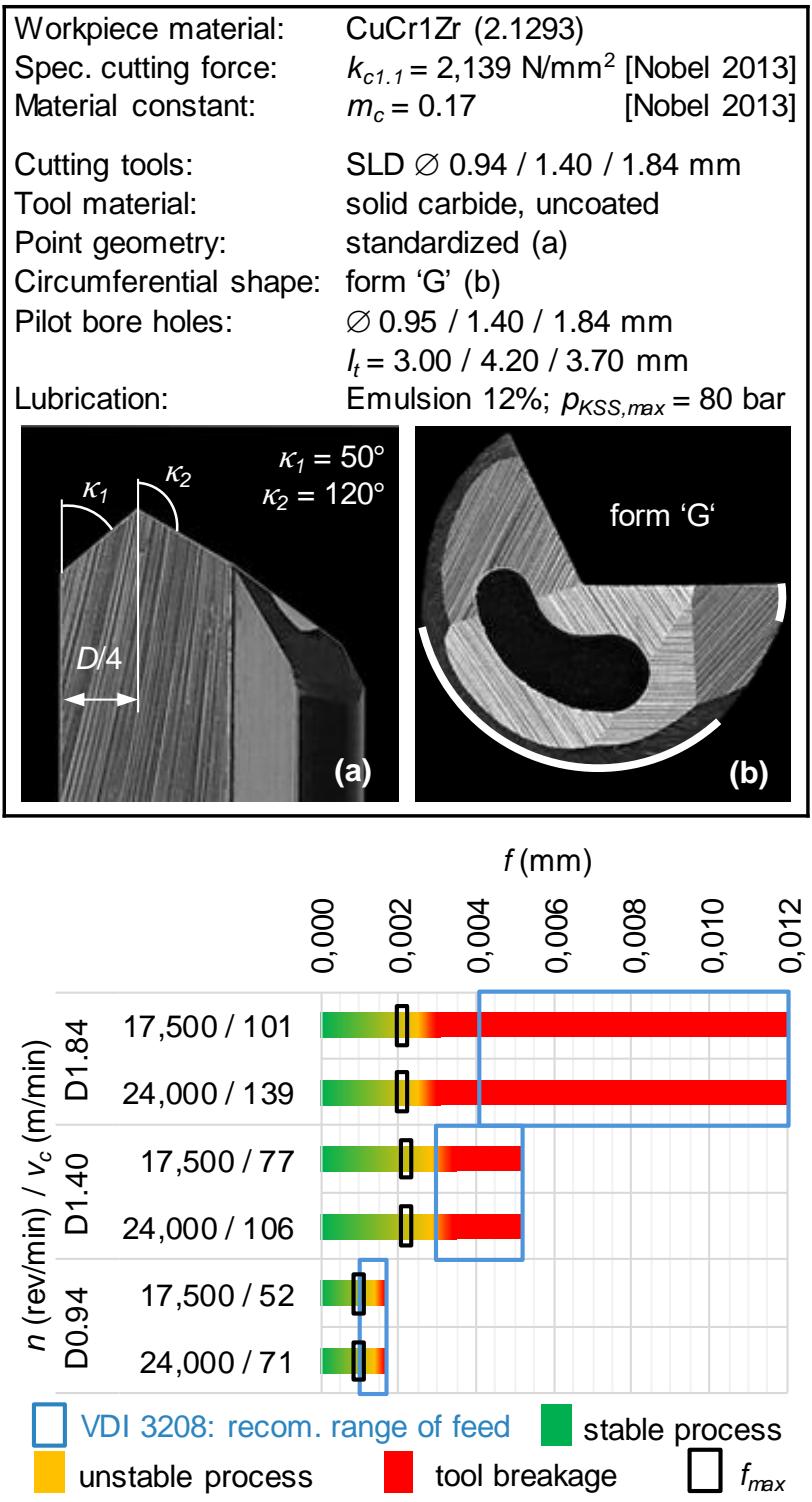

Fig. 1: Material characteristics of CuCr1Zr, tool tip design and areas of applicable process parameters limited by chip shapes in conventional SLD under given process constraints deriving from initial drilling tests.

The objective of this work is to demonstrate the positive effects of a low-frequency vibration support (in contrast to e.g. high-frequency applications beyond $17.5 \mathrm{kHz}$ ), generated by piezoelectric principle, in the machining of age-hardened copper-zirconium with single-lip deep hole drills at small diameters down to $0.94 \mathrm{~mm}$ (micro-drilling). Thereof resulting effects, as the significantly improved chip formation and in consequence a considerable enhancement in productivity, are demonstrated.

\section{GIVEN CIRCUMSTANCES AND SELECTION OF APPROPRIATE PROCESS PARAMETERS}

The IFT (TU Wien) developed a multi-axis vibration table that generates an oscillation movement of the workpiece or tool fastened on it, hence enabling a multiaxial hybrid machining. By the use of motion controlled piezo stacks, the frequency $f_{V S}$ (up to $500 \mathrm{~Hz}$ ) and amplitude $A_{V s}$ (up to $30 \mu \mathrm{m}$ ) of two spatial axes can be exactly set. Additionally, a balancing mass can be activated, in case it is necessary to protect the surrounding machine structure from undesired vibrations. An amplifier was developed to drive the 32 piezo actuators in total that are engaged for the exact axial positioning of the two moving plates inside the vibration table (the vibrating and the balancing mass; 8 actuators are applied per plate and spatial axis, separated to or rather placed at both exterior sides of the respective axis and plate). The mechanical bearing consists of flat air bearings to prevent a tilting in perpendicular direction to the piezo actuators' axes; a flat seal combined with sealing air provides protection against fluids. The casing dimensions are $350 \mathrm{~mm} \times 350 \mathrm{~mm}$, while the external vibration plate, on which the workpiece/tool is mounted, is dimensioned by $160 \mathrm{~mm} \times 160 \mathrm{~mm}$. A sectional view of the CAD-model of the vibration table is depicted in Fig. 2.

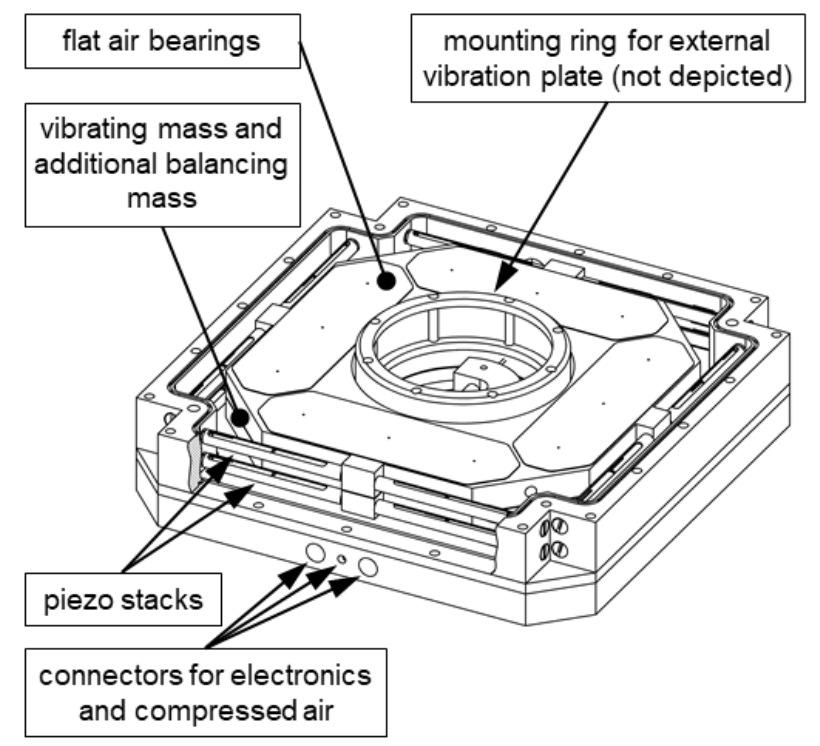

Fig. 2: Sectional view of CAD-model of the developed vibration table by IFT.

For the specific purpose in the present case, that being a single-axis drilling operation, the vibration table is mounted in a five-axis machining center (with its $A$-axis rotated by $90^{\circ}$; cf. section on experimental cutting tests), with only one of its vibration axes driven (the one in longitudinal direction of the machining center's vertical spindle respective the drilling tool). So, the vibration support or rather the superposition with a relative oscillating movement is performed by the workpiece, while at the same time the tool is providing the constant feed coming from the machine spindle. For the given arrangement, the highest reachable amplitudes were measured at a frequency of $f_{v s}=225 \mathrm{~Hz}$, with $A v s=12 \mu \mathrm{m}$ for a sine-wave electric power signal supply and $A v s=16 \mu \mathrm{m}$ for a rectangular-wave electric power signal supply at the piezo drives.

A kinematic model was created in MATLAB and LabVIEW to gain better knowledge of the interaction between cutting tool and workpiece and thereof resulting relations, due to additional vibration support. A 3D-plot of the interaction between SLD's cutting tip and workpiece surface, superimposed with a sine-wave, for two rotations of the tool is depicted in Fig. 3. Note: The conducted calculations and plots are solely quoted for $D=0.94 \mathrm{~mm}$ and a sinusoidal vibration support form.

Two characteristic factors describe the tool and workpiece engagement. The so-called amplitude ratio $K_{A}$ is defined as the ratio between the peak-to-peak amplitude $A_{v s, p-p}$ of the vibration and the feed $f$. For chip breakage, $K_{A} \geq 1$ has to theoretically be selected (intersected chip). The second factor is $K_{f}$, the so-called frequency ratio factor, which is defined as the ratio between the frequency of the vibration $f_{V S}$ and the rotational frequency $f_{n}$. In the present 
investigations, considering the given constraints, $K_{f}$ becomes lower than 1. Fig. 4 depicts the flow diagram for adoption of optimized process parameters. The nomenclature as well as the underlying calculation formulas for the flowchart and the following simulations are quoted in Fig. 5.

\begin{tabular}{|ll|}
\hline Cutting tool: & SLD $\varnothing 0.94 \mathrm{~mm}$ \\
Revolution speed: & $n=24,000 \mathrm{rev} / \mathrm{min}$ \\
Feed: & $f=19 \mu \mathrm{m}$ \\
Vibration support: & $f_{V S}=225 \mathrm{~Hz}$ \\
& $A_{V S}=12 \mu \mathrm{m}$ \\
\hline
\end{tabular}

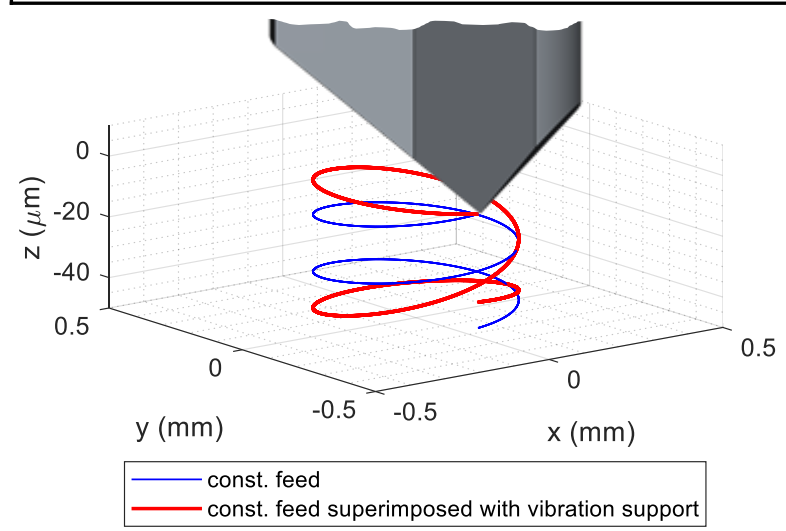

Fig. 3: Exemplary three-dimensional illustration of the interaction of SLD's cutting tip and workpiece surface with superimposed sinusoidal vibration support.

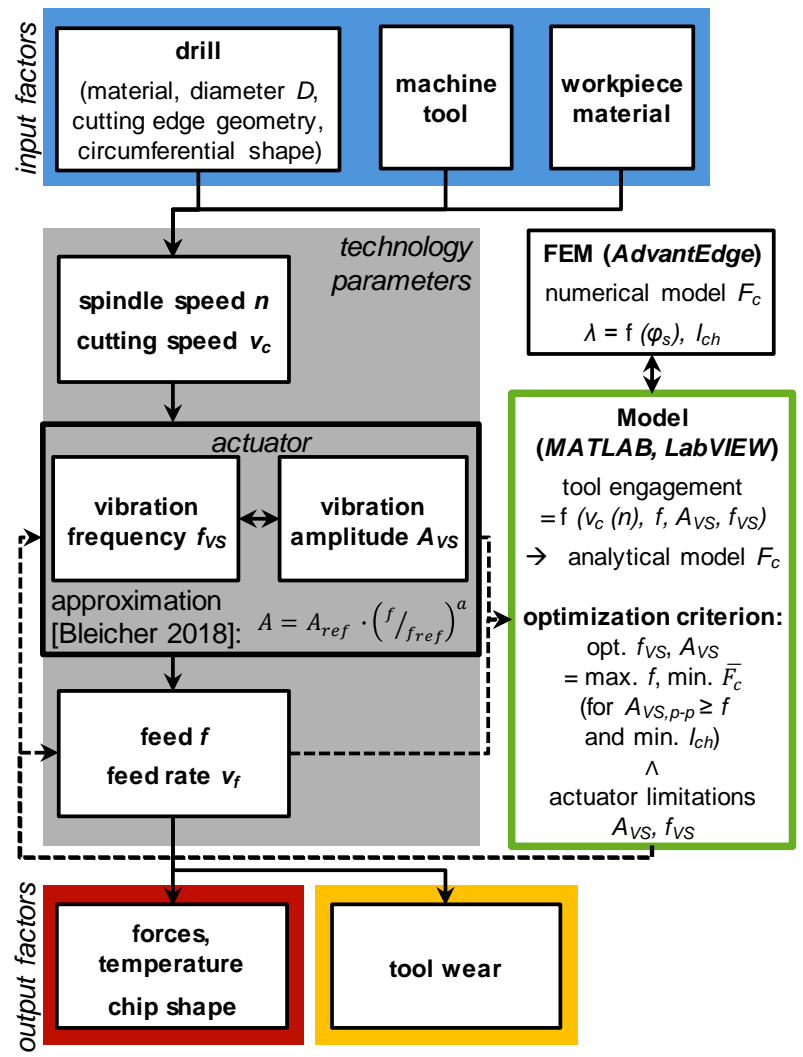

Fig. 4: Flowchart for the selection of appropriate process parameters (cutting and vibration support parameters). (i: 1 - outer cutting edge; 2 - inner cutting edge)

$A_{i} \quad \ldots$ area of cut $\left(\mathrm{mm}^{2}\right)$

$a_{p, i} \quad$... cutting depth ( $\left.\mathrm{mm}\right)$

$A_{V S} \quad \ldots$ amplitude vibration support $(\mu \mathrm{m})$

$b_{i} \quad$... width of cut $(\mathrm{mm})$

D $\quad$... tool diameter $(\mathrm{mm})$

f $\quad$... feed $(\mu \mathrm{m}, \mathrm{mm})$

$F_{c} \quad$... cutting force $(\mathrm{N})$

$f_{n} \quad \ldots$ rotational frequency $=n / 60(\mathrm{~Hz})$

$f_{V S} \quad$... frequency vibration support $(\mathrm{Hz})$

$h_{i} \quad \ldots$ thickness of cut, uncut chip thickness $(\mathrm{mm})$

$k_{c 1.1} \quad$... ref. value of spec. cutting force $\left(\mathrm{N} / \mathrm{mm}^{2}\right)$

$k_{c, i} \quad \ldots$ specific cutting force $\left(\mathrm{N} / \mathrm{mm}^{2}\right)$

$K_{A} \quad \ldots$ amplitude ratio $={ }^{A_{V S, p-p}} / f(-)$

$K_{f} \quad \ldots$ frequency ratio $=f_{V S} / f_{n}(-)$

$I_{c h} \quad \ldots$ chip length $(\mathrm{mm})$

$I_{f} \quad$... drilling length $(\mathrm{m})$

$I_{t} \quad$... drilling depth $(\mathrm{mm})$

$m_{c} \quad$... material constant (-)

$n \quad$... revolution speed ( $\mathrm{rev} / \mathrm{min})$

$p_{K S S} \quad \ldots$ cutting fluid pressure (bar)

$Q \quad$... material removal rate $\left(\mathrm{mm}^{3} / \mathrm{min}\right)$

$r_{\beta, i} \quad \ldots$ cutting edge radius $(\mu \mathrm{m})$

$V B \quad \ldots$ average flank wear $(\mu \mathrm{m})$

$v_{c} \quad$... cutting speed $(\mathrm{m} / \mathrm{min})$

$v_{f} \quad \ldots$ feed rate $(\mathrm{mm} / \mathrm{min})$

$\kappa_{i} \quad \ldots$ angle of incidence $\left({ }^{\circ}\right)$

$\lambda \quad$... chip compression factor (-)

$\varphi_{S} \quad \ldots$ shear angle $\left({ }^{\circ}\right)$

$F_{c}=k_{c, 1} \cdot A_{1}+k_{c, 2} \cdot A_{2}=k_{c 1.1} \cdot b_{1} \cdot h_{1}^{1-m_{c}}+k_{c 1.1} \cdot b_{2} \cdot h_{2}^{1-m_{c}}=$ $=k_{c 1.1} \cdot \frac{a_{p, 1}}{\sin \kappa_{1}} \cdot\left(f \cdot \sin \kappa_{1}\right)^{1-m_{c}}+k_{c 1.1} \cdot \frac{a_{p, 2}}{\sin \kappa_{2}} \cdot\left(f \cdot \sin \kappa_{2}\right)^{1-m_{c}}=$ $=k_{c 1.1} \cdot D / 4 \cdot\left[\frac{1}{\sin \kappa_{1}} \cdot\left(f \cdot \sin \kappa_{1}\right)^{1-m_{c}}+\frac{1}{\sin \kappa_{2}} \cdot\left(f \cdot \sin \kappa_{2}\right)^{1-m_{c}}\right]$

$Q=A \cdot v_{c}=b \cdot h \cdot v_{c}=a_{p} \cdot f \cdot v_{c}={ }^{D} / 2 \cdot f \cdot v_{c}$

Fig. 5: Nomenclature and applied calculation formulas for cutting force and material removal rate.

Under consideration of selected (or, in most cases, limited) cutting speed and feed, appropriate vibration parameters $A v s$ and $f v s$ can be calculated by the criterion of minimizing the average cutting force and mechanical loads, which should remain below tool stability. The small drill diameters require high spindle speeds to achieve the cutting speeds. Hence, the dynamic capabilities of the actuator (cf. [Bleicher 2018]) limit the achievable amplitudes and frequencies. Therefore, $K_{f}$ was considered in a range of 0.4 to 0.7 . The plots in Fig. 6 depict calculated numeric results of average and maximum cutting forces for an amplitude ratio $K_{A}=1 \ldots 3$ (the different layers symbolize different values of $K_{A}$, with a resolution of 0.25 ) and a frequency ratio $K_{f}=0 \ldots 2$. 


\begin{tabular}{|ll|}
\hline Workpiece material: & CuCr1Zr \\
Cutting tool: & SLD $\varnothing 0.94 \mathrm{~mm}$ \\
Revolution speed: & $n=24,000 \mathrm{rev} / \mathrm{min}$ \\
Cutting speed: & $v_{c}=70.9 \mathrm{~m} / \mathrm{min}$ \\
Feed: & $f=19 \mu \mathrm{m}$ \\
Feed rate: & $v_{f}=450 \mathrm{~mm} / \mathrm{min}$ \\
\hline
\end{tabular}
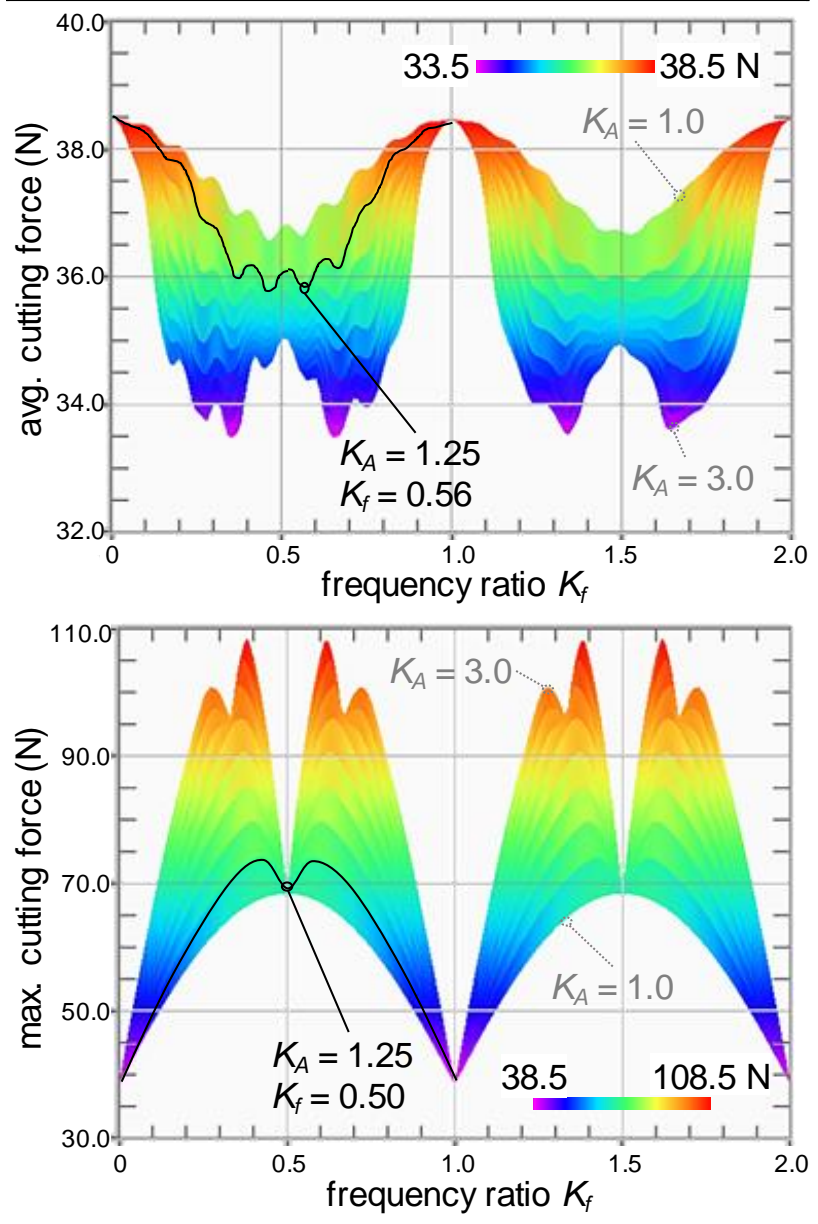

Fig. 6: Simulation plots for the determination of local optima of occurring cutting forces at different frequency and amplitude ratios.

Exemplary plots for chosen local optima (cf. Fig. 6) are depicted in Fig. 7, in order to illustrate the differences between conventional drilling and vibration-assisted drilling (VAD). They show the tool engagement or feed (blue colored areas) based on the angular position of the tool, and the arising variation of resulting cutting forces. From the start of drilling to five rotations of the tool, it becomes evident, that the area of uncut chip thickness results from three tool rotations. Due to the varying feed (and consequently the thickness of cut) in contrast to conventional machining without vibration support, it is possible to decrease the mean cutting force throughout the entire machining time, although the maximum cutting force may be higher than for conventional drilling. It has to be pointed out that the applied cutting parameters are definitely not reliably practicable without vibration support, as rapid failure of the fragile single-lip drill would occur due to the bad chipping behavior with consequential chip jamming etc.

Moreover, various FEM-simulations have been investigated in advance, especially concerning modal analyses of the single-lip drills and the effects on the shear angle due to the application of vibration support, cf. [Bleicher 2019]. Additionally, the influence of the tool's twisting subject to varying thickness of cut was also theoretically examined, but assessed as negligible.

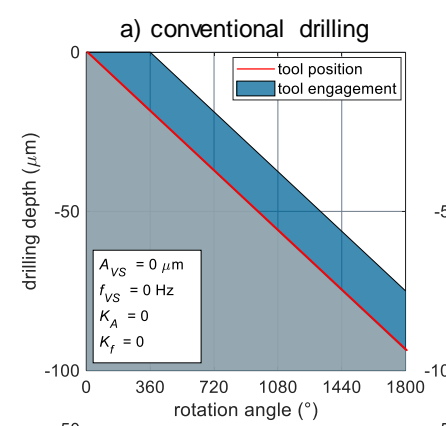

b) vibration-assisted drilling
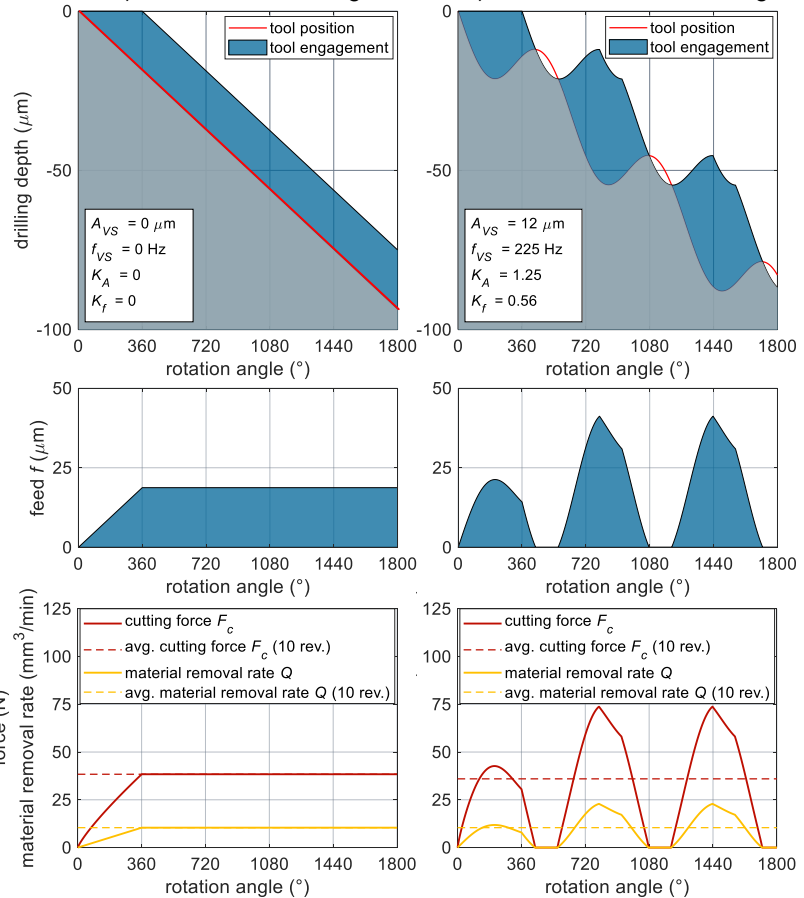

Fig. 7: Simulation plots for various quantities/relationships during the drilling process (five full rotations of the tool depicted); a) conventional drilling without vibration support, b) vibration-assisted drilling.

\section{EXPERIMENTAL CUTTING TESTS}

Based on the theoretic calculations and on preceding empiric investigations, the chosen parameters for $D=0.94 \mathrm{~mm}$ have been adapted for $D=1.40 \mathrm{~mm}$ and $D=1.84 \mathrm{~mm}$, with a fixed feed rate of $v f=450 \mathrm{~mm} / \mathrm{min}$ (results in a mere drilling time of $4.53 \mathrm{~s}$ for a drilling depth of $I_{t}=34 \mathrm{~mm}$ ) as declared objective. The focus therefore was the ensuring of chip breakage, which was achieved by the respective combination of cutting and vibration support parameters. The process parameters for the used tool diameters are listed in Tab. 1.

Tab. 1: Cutting and vibration support parameters.

\begin{tabular}{l|r|r|r}
\hline Parameter (Unit) & \multicolumn{3}{|c}{ Value } \\
\hline Tool diameter $D(\mathrm{~mm})$ & 0.94 & 1.40 & 1.84 \\
\hline Revolution speed $n(\mathrm{rev} / \mathrm{min})$ & 24,000 & 18,200 & 17,300 \\
\hline Cutting speed $v_{c}(\mathrm{~m} / \mathrm{min})$ & 70.9 & 80.0 & 100.0 \\
\hline Feed $f(\mu \mathrm{m})$ & 19 & 25 & 26 \\
\hline Feed rate $v_{f}(\mathrm{~mm} / \mathrm{min})$ & 450 & 450 & 450 \\
\hline Vibration frequency $f_{v S}(\mathrm{~Hz})$ & 225 & 225 & 225 \\
\hline Vibration amplitude $A_{v S}(\mu \mathrm{m})$ & 12 & 16 & 16 \\
\hline Frequency ratio $K_{f}(-)$ & 0.56 & 0.74 & 0.78 \\
\hline Amplitude ratio $K_{A}(-)$ & 1.26 & 1.28 & 1.23 \\
\hline
\end{tabular}

Experimental cutting tests were performed on a Hermle C42 $U$ machining center (max. spindle speed $n_{\max }=24,000 \mathrm{rev} / \mathrm{min}$; used experimental setup presented in Fig. 8). The specimens were of cuboid shape and, as introducing already mentioned, out of age-hardened $\mathrm{CuCr} 1 \mathrm{Zr}$. These were mounted on the vibration table, which in turn was mounted onto the indexing clamping system on the machine table, and orientated in the rotated way stated in the introductory section. The drilling depth for the shown specimen was $l_{t}=34 \mathrm{~mm}$, which results in $L / D$-ratios of 18 Special Issue on HSM2019 
(for $D=1.84 \mathrm{~mm}$ ) up to 36 (for $D=0.94 \mathrm{~mm}$ ). Internal cutting fluid supply of the tools' kidney-shaped cooling channels is provided with $p_{K S S}=80$ bar at an oil content of $12 \%$.

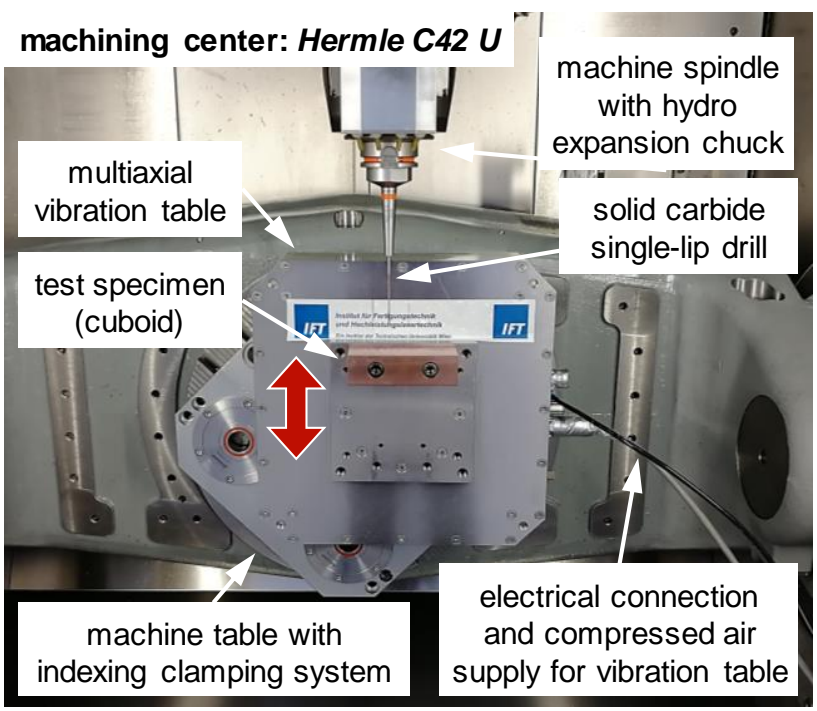

Fig. 8: Experimental test setup.

The produced chips for application of the above noted parameter sets (cf. Tab. 1) are depicted in Fig. 9, bottom. Due to appropriate implementation of low-frequency vibration to the workpiece, it is possible to generate short chips that are less harmful to the tool and the resulting bore wall's surface during their continuous removal along the tool's flute. As a result, it was possible to increase the productivity to the previously calculated feed rate of 450 $\mathrm{mm} / \mathrm{min}$ without the typically expectable tool failure due to long chips (exemplary chips depicted in Fig. 9, top), as they are common for the investigated copper-zirconium material. For the given parameters, this means an improvement of productivity by factors up to 20 (for $D=0.94 \mathrm{~mm}$ ) in comparison to the initial maximum values for given tool diameter and workpiece material (cf. Fig. 1).
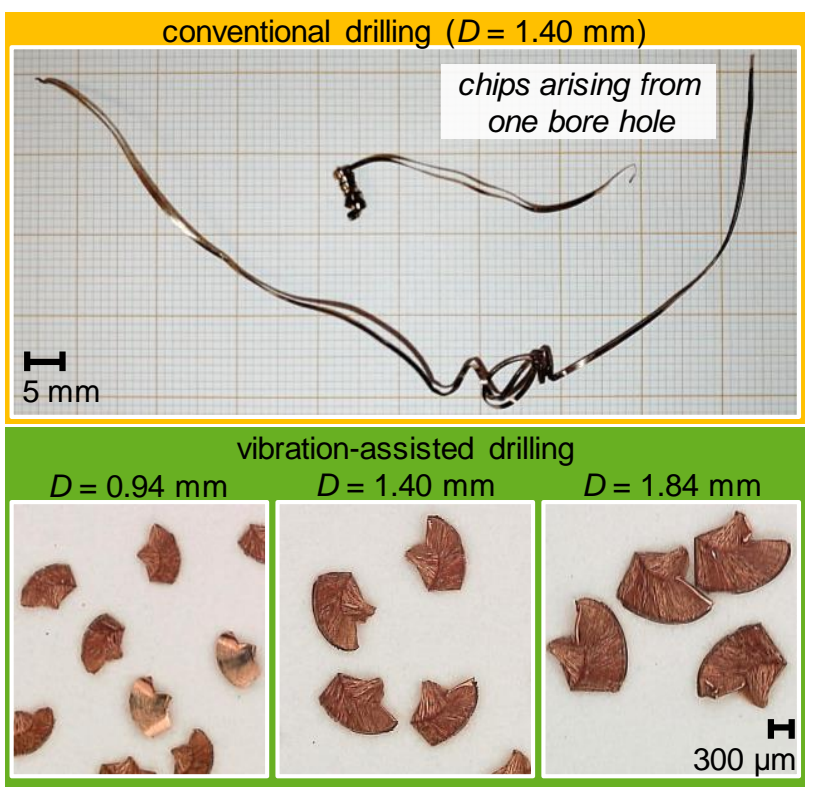

Fig. 9: Exemplary chips occurring for conventional deep hole drilling compared to vibration assisted drilling.
With the mentioned parameter combinations (Tab. 1), initial tool performance tests were conducted by the drilling of 145 bore holes for each tool diameter, resulting in a total drilling length of $l_{f}=4.93 \mathrm{~m}$. A Keyence $V W-9000$ and an Alicona Infinite Focus G5 were used for accompanying recordings of the tool wear. As visible in Fig. 10, tool wear in this early state is hardly apparent. Next to conventional friction marks on the rake face, wear marks on the flank face barely exist. The stable cutting edge radii (see boxes in Fig. 10, right) undergirds the favorable application of low-frequency vibration support for the present machining conditions.
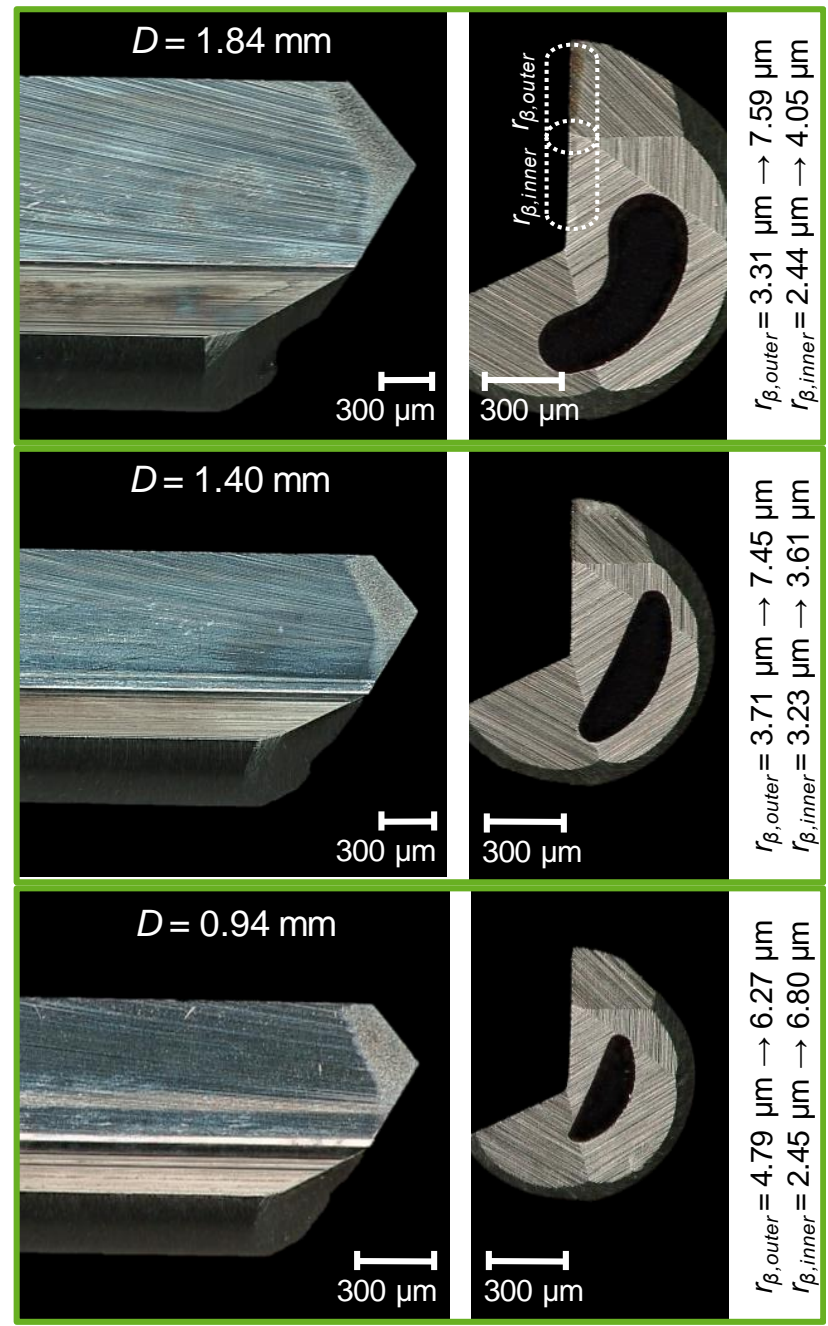

Fig. 10: Recordings of tool wear for the initial state and after 145 bore holes $\left(l_{f}=4.93 \mathrm{~m}\right)$.

Consequently, extensive tool life tests were performed with $D=1.40 \mathrm{~mm}$ (corresponds to arithmetic mean of the investigated tool diameter range). For this purpose, the process parameters have been optimized for the given environmental conditions. The spindle speed was increased, and in consequence the feed has been decreased (while maintaining the feed rate of $v_{f}=450 \mathrm{~mm} / \mathrm{min}$ ), so that the vibration frequency could also be lowered while still meeting the needs of a local optimum frequency ratio (Fig. 11, top). 1,500 bore holes were defined as objective criterion (resulting in a total drilling length of $l_{f}=51.0 \mathrm{~m}$ ), and arising chips as well as tool wear were evaluated in the before stated way. Two different variations have been conducted: First, the already established configuration with the long-chipping CuCr1Zr and $p_{K S S, \max }=80$ bar was used for the conduction of the tool life test (recorded tool wear and chip shape, see 
Fig. 11a). The second test run was executed by application of a significantly lower cutting fluid pressure of $p_{K S S}=20$ bar (recorded tool wear and chip shape, Fig. 11b). This should demonstrate that due to the improved chip shape, the evacuation of chips out of the bore hole does not require substantially high cutting fluid pressures, as usually indispensable for a conventional SLD process.

\begin{tabular}{|ll|}
\hline Cutting tool: & SLD $\varnothing 1.40 \mathrm{~mm}$ \\
Revolution speed: & $n=22,750 \mathrm{rev} / \mathrm{min}$ \\
Cutting speed: & $v_{c}=100.1 \mathrm{~m} / \mathrm{min}$ \\
Feed: & $f=20 \mu \mathrm{m}$ \\
Feed rate: & $v_{f}=450 \mathrm{~mm} / \mathrm{min}$ \\
Vibration support: & $f_{V S}=200 \mathrm{~Hz}$ \\
& $A_{V S}=12 \mu \mathrm{m}$ \\
\hline
\end{tabular}
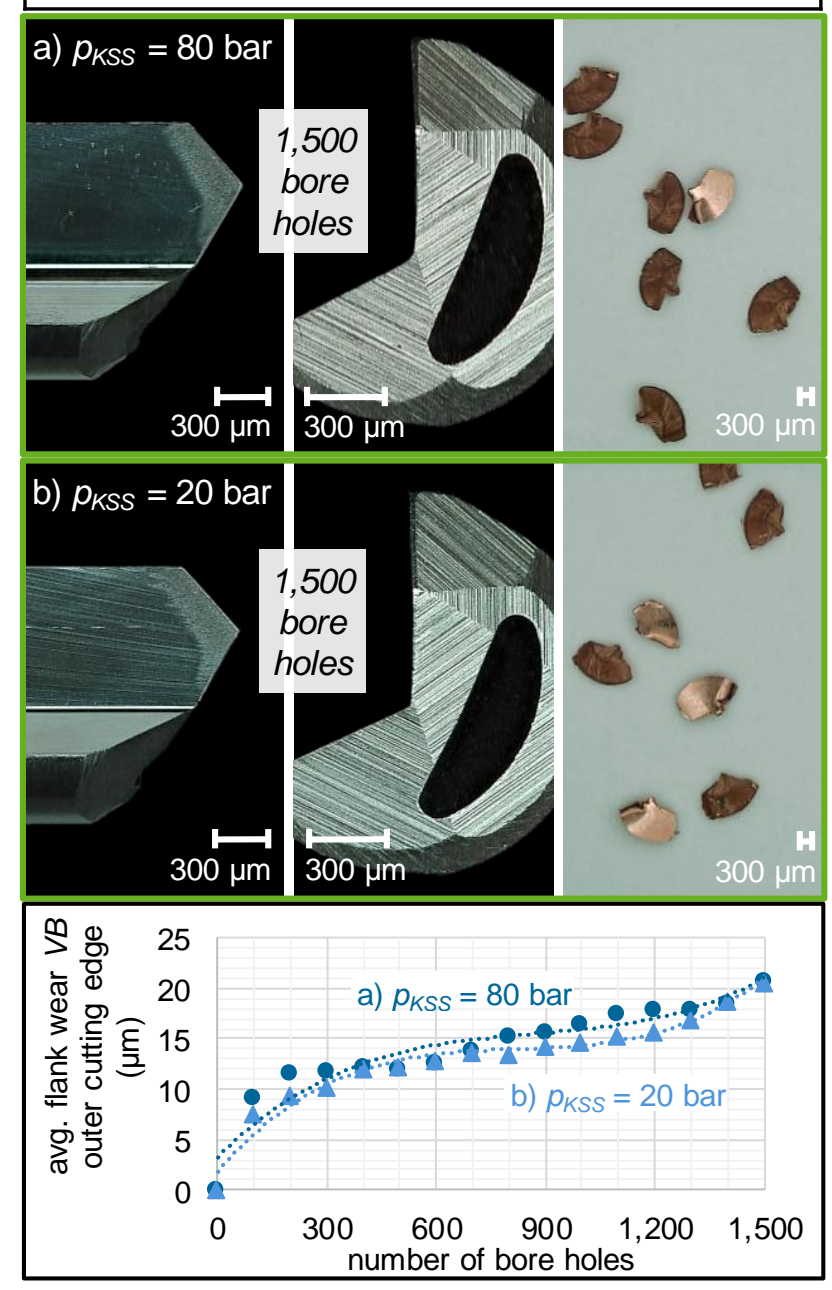

Fig. 11: Analyses of tool wear after 1,500 bore holes $\left(l_{f}=51.0 \mathrm{~m}\right)$ and chip shapes for SLDs of $D=1.40 \mathrm{~mm}$ and different experimental configurations;

a) $p_{K S S}=80$ bar, b) $p_{K S S}=20$ bar.

Moreover, Fig. 11 shows the progress of average flank wear along the outer cutting edges (which was chosen as the most compelling value therefore), conducted after every hundredth bore hole, for both the investigated experimental configurations. The material $\mathrm{CuCr} 1 \mathrm{Zr}$ appears to have - not least because of the effective application of appropriate vibration support - little abrasive wear characteristics, as the wear marks on the single-lip drills even after 1,500 bore holes are still in a range that allows high qualities regarding the diameter and surface roughness of the produced bore holes (Fig. 12 and Fig. 13). The optical measurements of the beforehand sliced specimens were conducted on an Alicona Infinite Focus G5 for every hundredth bore hole. Besides that, the investigated bore holes show acceptable or rather reasonable straightness deviation for the given experimental test conditions. Furthermore, due to the effective chip breakage coming from the vibration support, it was possible to reduce the

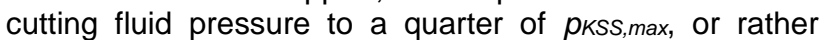
$p_{K S S}=20$ bar, whereas still no process interference was recognizable and the tool's wear marks were similar to the first test run with maximum cutting fluid pressure.
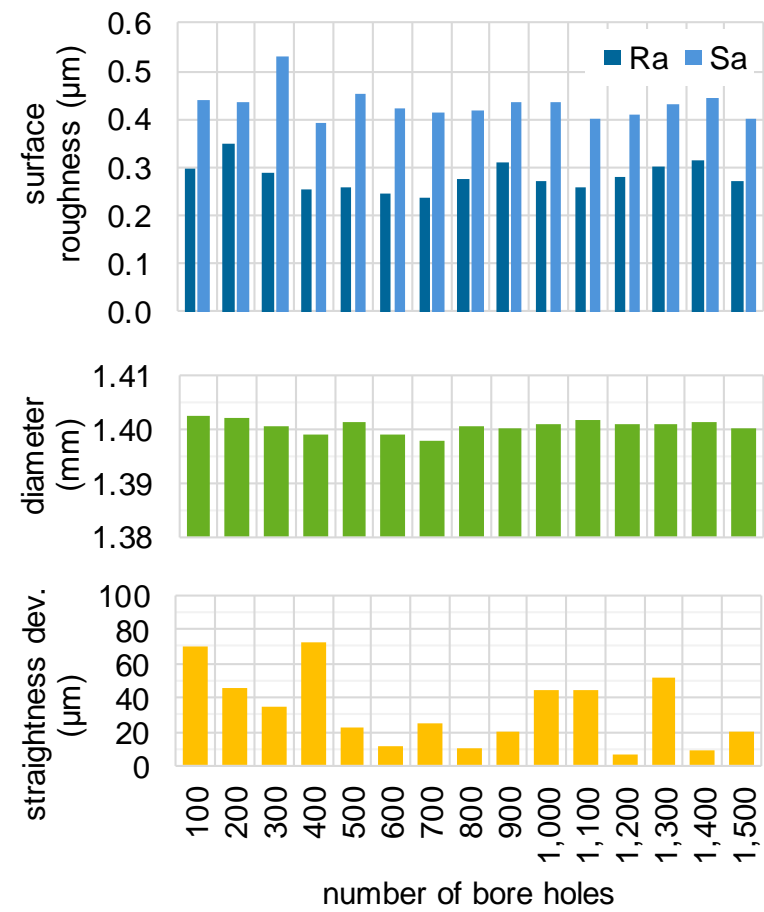

Fig. 12: Analyses of bore hole quality for the tool life test run with pkss $=80$ bar.
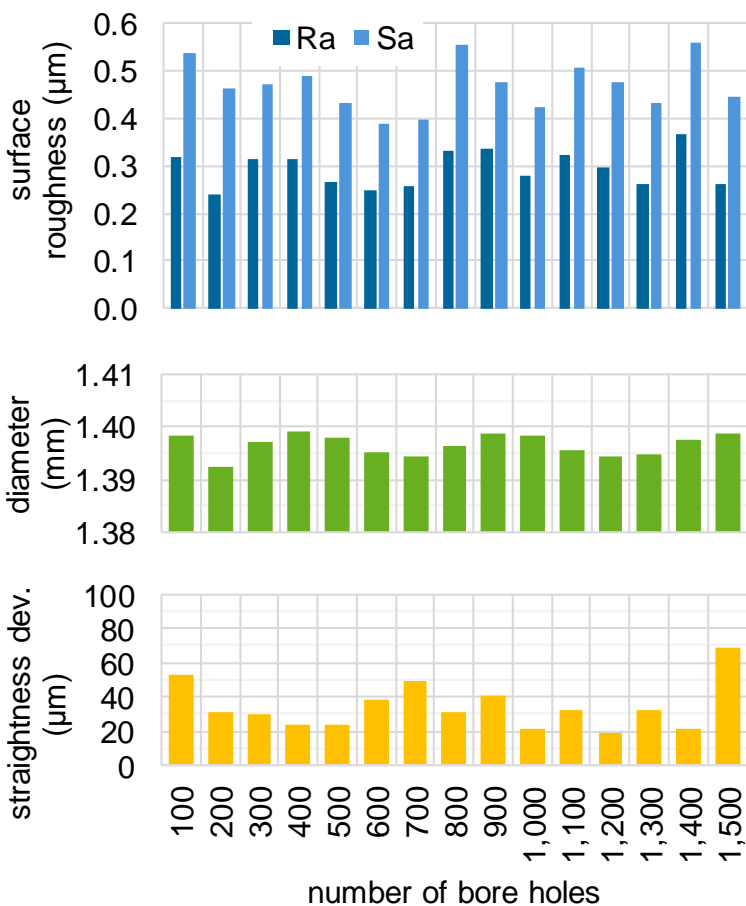

Fig. 13: Analyses of bore hole quality for the tool life test run with $p_{K S S}=20$ bar. 


\section{CONCLUSION AND OUTLOOK}

The realized theoretical calculations and conducted experimental cutting tests confirm the positive effects of application of vibration support at low frequencies with high amplitudes in the field of deep hole drilling, in the specific case a single-lip drilling (down to micro-drilling) of long-chipping copper-zirconium. Hence, the chip formation is significantly improved, with small chips that do not affect/damage the tool or workpiece and can be easily removed along the tool's flute throughout the bore hole. Moreover, excellent surface qualities can be expected and the arising tool wear is minimized. Therefore, the productivity has been increased to a level where conventional single-lip drilling would have by far reached its limitations. Future research works should focus on new actuator systems to enable higher amplitudes at frequencies up to $500 \mathrm{~Hz}$.

\section{REFERENCESS}

[Biermann 2018] Biermann, D., et al. Deep hole drilling. CIRP Annals Manufacturing Technology, 2018, Vol. 67, No. 2, pp. 673-694. ISSN 17260604

[Bleicher 2018] Bleicher, F., et al. Vibration assisted drilling of CFRP/metal stacks at low frequencies and high amplitudes. Production Engineering, 2018, Vol. 12, No. 2, pp. 289-296. ISSN 18637353

[Bleicher 2019] Bleicher, F., Reiter, M. and Brier, J. Increase of chip removal rate in single-lip deep hole drilling at small diameters by low-frequency vibration support. CIRP Annals Manufacturing Technology, 2019, Vol. 68, No. 1 , in press.

[Brehl 2008] Brehl, D.E. and Dow, T.A. Review of vibrationassisted machining. Precision Engineering, 2008, Vol. 32, No. 3, pp. 153-172. ISSN 01416359

[DKI 2005] Deutsches Kupferinstitut. Werkstoffdatenblatt CuCr1Zr. 2005.

[DKI 2010] Deutsches Kupferinstitut. Richtwerte für die spanende Bearbeitung von Kupfer und Kupferlegierungen. 2010.

[Nobel 2013] Nobel, C. and Klocke, F. Entwicklung einer Hochleistungszerspanung für schwerzerspanbare bleifreie Kupferknet- und -gusslegierungen. Aachen: WZL, RWTH Aachen, 2013.

[Okamura 2006] Okamura, K., et al. Low-Frequency Vibration Drilling of Titanium Alloy. JSME International Journal Series C, 2006, Vol. 49, No. 1, pp. 76-82. ISSN 13447653

[Pecat 2014] Pecat, O. and Brinksmeier, E. Tool wear analyses in low frequency vibration assisted drilling of CFRP/Ti6Al4V stack material. Procedia CIRP, 2014, Vol. 14, pp. 142-147. ISSN 22128271

[Sadek 2014] Sadek, A., Meshreki, M. and Attia, M.H. Effect of tool kinematics on the drilling forces and temperature in low frequency high amplitude vibration assisted drilling. Proceedings of the ASME 2014 International Mechanical Engineering Congress and Exposition, 2014, Vol. 2A, pp. 1-7. ISBN 978-0-7918-4643-8

[VDI 2014] Verein Deutscher Ingenieure e.V. VDI 3208 Deep-hole drilling with gun drills. Berlin: Beuth Verlag, 2014. 